\title{
P003. NSAIDs for symptomatic treatment of headache
}

\author{
Giannapia Affaitati ${ }^{1 *}$, Paolo Martelletti ${ }^{2}$, Mariangela Lopopolo ${ }^{1}$, Claudio Tana ${ }^{3}$, Francesca Massimini ${ }^{4}$, \\ Francesco Cipollone ${ }^{1}$, Domenico Lapenna ${ }^{1}$, Maria Adele Giamberardino ${ }^{1}$, Raffaele Costantini ${ }^{5}$ \\ From Abstracts from the 1st Joint ANIRCEF-SISC Congress \\ Rome, Italy. 29-31 October 2015
}

\section{Background and aims}

Clinical observations suggest that the use of non-steroidal anti-inflammatory drugs (NSAIDs) for symptomatic treatment of headache is not in line with recommendations by international guidelines [1]. The aim of the study was to evaluate NSAIDs use for episodic headache at the Headache Centre of the Chieti University in the period: January 2000-February 2013.

\section{Methods}

A retrospective evaluation was carried out on 6,443 records of episodic migraine $(n=2,330)$, tension-type headache $(\mathrm{TTH}) \quad(\mathrm{n}=807)$ and migraine + TTH $(n=3,306)$ sufferers relative to NSAID use for the acute attack: type of NSAID/s; uni- or poly-therapy (one or more NSAID/s in different attacks) and NSAID efficacy (subjective scale: complete (C), partial (P) or absent (A) pain relief at 2 hours), at the first visit and 1-year follow-up.

\section{Results}

In migraine patients, $80 \%$ had been NSAID users in the past year. The three most frequently employed molecules were: nimesulide (57\%), ketoprofen (25\%) and ibuprofen (24\%). Complete vs. incomplete/absent efficacy was significantly higher for all three $(\mathrm{p}<0.0001)$. NSAIDs were replaced with triptans in $53 \%$ of the patients at the first visit; after 1 year: a significant spontaneous return to NSAIDs occurred in $56 \%$ of the cases $(\mathrm{p}<0.0005)$ for inadequate efficacy/side effects $(62 \%)$ or difficulty in obtaining prescription (38\%) of triptans from the family doctor. In TTH patients, $90 \%$ were

\footnotetext{
* Correspondence: gp@unich.it

${ }^{1}$ Headache Centre, Department of Medicine and Science of Aging, "G.

D'Annunzio" University of Chieti, Chieti, Italy

Full list of author information is available at the end of the article
}

NSAID users; preferences were: nimesulide (48\%), ketoprofen (47\%) and diclofenac (19\%); complete vs. incomplete/absent efficacy was significantly higher for the first two $(\mathrm{p}<0.02)$. Replacement with analgesics was performed in $24 \%$ of the patients at the first visit; at oneyear follow-up a spontaneous return to NSAIDs occurred in $29 \%$ of the cases for inadequate efficacy of the non-NSAID therapy. In Migraine + TTH patients who were not able to distinguish the nature of their attack at the beginning of the pain, $89 \%$ were NSAID users; the three most frequently employed molecules were: nimesulide (44\%), ibuprofen (42\%) and ketoprofen (38\%); complete vs. incomplete/absent efficacy was significantly higher for all three $(0.001<\mathrm{p}<0.0001)$. Replacement with analgesics was prescribed to $31 \%$ of the patients at the first visit; at one-year follow-up a spontaneous return to NSAIDs occurred in $37 \%$ of them for inadequate efficacy of the non-NSAID therapy.

\section{Conclusions}

NSAID use in episodic headache is higher than could be hypothesized based on guidelines [2]. NSAID role/efficacy, particularly in migraine, should be better understood. A higher degree of sensitization towards different treatment options for headache should also be promoted in the medical environment [3].

Written informed consent to publish was obtained from the patient(s).

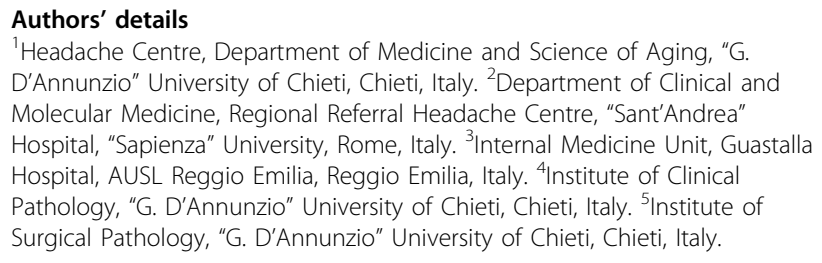
zero/1.0/) applies to the data made available in this article, unless otherwise stated. 


\section{References}

1. Silberstein SD, Stirpe JC: COX inhibitors for the treatment of migraine. Expert Opin Pharmacother 2014, 15(13):1863-1874.

2. Motola D, Vaccheri A, Silvani MC, Poluzzi E, Bottoni A, De Ponti F, Montanaro N: Pattern of NSAID use in the Italian general population: a questionnaire-based survey. Eur J Clin Pharmacol 2004, 60(10):731-738.

3. Taylor FR, Kaniecki RG: Symptomatic treatment of migraine: when to use NSAIDs, triptans, or opiates. Curr Treat Options Neurol 2011, 13(1):15-27.

doi:10.1186/1129-2377-16-S1-A162

Cite this article as: Affaitati et al:: P003. NSAIDs for symptomatic

treatment of headache. The Journal of Headache and Pain 2015

16(Suppl 1):A162.

\section{Submit your manuscript to a SpringerOpen ${ }^{\circ}$ journal and benefit from:}

- Convenient online submission

- Rigorous peer review

- Immediate publication on acceptance

- Open access: articles freely available online

- High visibility within the field

- Retaining the copyright to your article

Submit your next manuscript at $\gg$ springeropen.com 